\title{
O JORNALISMO COMO CAMPO SOCIAL E COMO DOMÍNIO DE FORMAÇÃO
}

\author{
ManUel Pinto*
}

\section{RESUMO}

A complexidade crescente da vida social, a proliferação das fontes e das formas de aceder, gerir e fazer circular a informação, as transformações no plano económico-social e no plano cultural e ético induzidas pelas inovações tecnológicas tornam necessário repensar o quadro em que ocorre a formação inicial e contínua dos profissionais da comunicação e, em especial, dos jornalistas. Neste texto, recorreu-se ao conceito de campo proposto por Bourdieu para sublinhar os dinamismos do campo jornalístico e as suas interaç̧ões com os restantes campos sociais, destacando os desafios, condicionantes, requisitos e orientaçōes que as instituições de ensino superior que fazem formação de jornalistas não poderão deixar de equacionar. Sustenta-se a necessidade de manter uma permanente tensão entre o contacto e a familiarização com o terreno da prática profissional, por um lado, e com o distanciamento crítico que os instrumentos téricos e metodológicos possibilitam, por outro lado.

Nos últimos anos tem vindo a adquirir crescente expressão um discurso que não se limita a sublinhar a crise do jornalismo, mas que aponta mesmo para o seu fim (Martínez-Albertos, 1997; Ramonet, 1999). Até o muitas vezes citado texto de Gabriel Garcia Márquez, El Mejor Oficio del Mundo, acaba por soar, embora com matizes, a um dobre de finados pelo jornalismo ou, pelo menos, por um certo jornalismo.

* Professor do Departamento de Ciências da Comunicaçăo da Universidade do Minho E-mail: mpinto@iec.uminho.pt 
Ignacio Ramonet sustenta que «o sistema deixou de necessitar de jornalistas, os quais perderam a sua especificidade». "Só quem anda de olhos fechados é que não vê isso", diz ele, de forma peremptória (1999 1). Para quê jornalistas se os departamentos e serviços oficiais e oficiosos, públicos e privados podem fazer o trabalho daqueles, incorporando o seu 'know how'? Não é que não possam continuar a existir redacções em que os jornalistas trabalham. Simplesmente, o trabalho informativo estrategicamente concebido, meticulosamente preparado e profissionalmente realizado a montante remeteria cada vez mais os jornalistas para um papel que, na melhor das hipóteses, é o de difusores/fornecedores de informação e de legitimadores de mensagens controladas na fonte.

No seu livro El Ocaso del Periodismo, Martínez-Albertos considera que 'os jornalistas perderam, de facto, o rumo do seu ofício e cada vez sabem menos qual é o seu papel no grande teatro do mundo', além de que 'as novas sociedades emergentes já não precisam do jornalismo para sobreviver' (1997: p.18).

Ao debruçarmo-nos sobre a pertinência e significados destes discursos, devemos perguntar-nos, em primeiro lugar, de que jornalismo estamos a falar, uma vez que, felizmente, não se pode medir tudo e todos pela mesma bitola 2. Por outro lado, convém atender ao posto de observação a partir do qual tais discursos são formulados 3. Muitos lamentos podem decorrer da dificuldade de descortinar, na vertigem informativa, os sinais novos e as permanências; da incerteza que paira sobre o futuro daquele que é tido como o suporte informativo por excelência, o jornal diário impresso; ou da onda mercantilista que se vai infiltrando até nas áreas mais preservadas dos media.

A emergência e alastramento desse novo meio-ambiente que é a Internet, com um vasto cortejo de propriedades técnicas e um não menos vasto quadro de conotações e de símbolos constituem, porventura, outro e poderoso factor crítico. Cada vez em maior escala, a comunicação mediada por computador permite às fontes informativas, designadamente àquelas que se encontram institucionalmente organizadas e apetrechadas, fazer chegar directamente ao grande público as suas informaçōes, sem necessi-

1 In 'La Fin du Journalisme - Débat avec Ignacio Ramonet'. Entrevista dada a ACRIMED - Action Critique Médias, em 16 de Fevereiro de 1999 (www.samizdat.net/acrimed/ bulletin/Ramonet.html).

2 Ramonet, por exemplo, formula as suas denúncias e expressa os seus desencantos recorrendo sobretudo ao jornalismo.

3 O professor e jornalista Carlos Chaparro interrogava-se recentemente: «O que acabou de verdade - o jornalismo dos sonhos libertários e justiceiros, em alguns casos sonhos simplesmente poéticos da juventude generosa e imaginativa? Ou terá acabado a maravilhosa utopia em que acreditei?» (in $O$ Ribatejo, 22.7.99) 
dade da intermediação jornalística: dos seus processos de notificação e dos seus filtros de selecção e hierarquização. A par do encantamento e sedução que decorre da profusão de fontes e da diluição da noção de periodicidade, inerente à produção jornalística tradicional, emerge a antevisão - se não já a verificação - da desinformação, da informação interessada, da navegação sem destino no oceano informativo.

Diante deste cenário de mudanças, considero, por conseguinte, que não estaremos tanto perante o ocaso do jornalismo como, sobretudo, diante de um processo, indubitavelmente crítico e complexo, de procura e de recomposição, o que pressupõe um jogo permanente e conflitos inevitáveis entre modalidades e géneros novos e antigos e uma redefinição das relaçōes deste campo com outros campos da vida social, em busca de novos equilíbrios. A instituição universitária é, ou deve ser, neste quadro, não apenas instância de observação e de análise, mas também agente activo das mudanças em curso, competindo-lhe, antes de mais, accionar os instrumentos analíticos que ajudem a compreender melhor o que se está a desenhar.

Neste artigo ${ }^{4}$, procuramos, precisamente, reflectir sobre alguns pressupostos e orientações que devem informar a formação em jornalismo, no quadro actual. As observações que exprimi atrás permitem ter a noção de que se trata de uma tarefa difícil, necessariamente balizada por dois aspectos: de um lado, a necessária e permanente atenção ao que se passa no terreno, aos novos fenómenos e processos que dialogam com (e questionam) os conhecimentos e métodos adquiridos; do outro lado, o não menos necessário distanciamento crítico face ao que se passa, o constante investimento na capacidade de ler o que se esconde por detrás das aparências e do espectáculo do mundo. É, certamente, um caminho exigente, que temos procurado percorrer, nos últimos anos.

Para esta reflexão, e dadas as limitações deste texto, limito-me a considerar aqui o jornalismo não tanto como uma profissão, como uma arte ou como um técnica, mas sobretudo como um campo social autónomo e como disciplina e formação académica, cuja razão de ser é precisamente aprofundar as bases teóricas e metodológicas exigidas pela necessidade e desafio de iluminar o lugar, papel e processos do Jornalismo nas sociedades contemporâneas.

De um ponto de vista histórico, o jornalismo é um fenómeno relativamente recente (Mathien, 1995). O seu estudo científico é-o ainda mais. Etimologicamente, o vocábulo 'jornalismo' remete-nos para a prática da

4 Este texto, numa versão distinta, integrou um capítulo do relatório por mim apresentado como requisito do concurso para um lugar de professor associado no grupo de Ciências da Comunicação, aberto em 1998 no Instituto de Ciências Sociais da Universidade do Minho. 
difusão quotidiana da informação. De facto, o termo refere-se ao substantivo jornal, originariamente um adjectivo que designa a vida / o ritmo diurno (diurnalis<diurnus). O jornal é, assim, em rigor, o jornal diário e reporta-se - digamo-lo assim - ao que ocorre de significativo e de interessante no espaço de um dia. Por extensão semântica, acaba por designar toda a actividade de produção e divulgação da informação de actualidade, marcada por um certo período temporal, de maior ou menor extensão 5 .

Em sentido restrito, o jornalismo pode ser entendido como uma ocupação e como uma actividade e uma técnica de recolha, elaboração e difusão de informação de actualidade através de meios de difusão colectiva, no quadro de organizações/instituiçōes próprias e em contextos sócio-culturais e políticos determinados.

A perspectiva de abordagem do jornalismo que aqui adopto é predominantemente uma perspectiva sociológica. Procura, assim, compreender a especificidade da actividade jornalística e dos jornalistas nas suas interacções com o sistema social global. De modo particular, trata de indagar quer as dimensões e modalidades em que essa actividade se configura como agência activa daquele sistema, quer aquelas em que é um produto instituído e configurado pelo quadro mais amplo em que se inscreve e de que faz parte. Distancio-me, assim, de orientações que procuram analisar e compreender este campo por si próprio, como se se tratasse de um sistema fechado, um território insularizado e desligado das mediações e intercâmbios com o sistema social envolvente. $O$ conceito de campo jornalístico, que Pierre Bourdieu aprofundou em trabalho recente (Bourdieu, 1994), pareceme constituir, nesta linha, bom enquadramento e ponto de apoio para ancorar o itinerário de reflexão sobre o jornalismo, itinerário que é necessariamente de aproximação, de interrogação, de compreensão.

\section{O Jornalismo como campo social autónomo}

O conceito de campo tem sido objecto de propostas de diferentes orientações teóricas e revela-se pertinente para analisar a posição do jornalismo no espaço social global. É consensual, entre os sociólogos, o contributo decisivo trazido por Pierre Bourdieu, para o aprofundamento e operacionalização desse conceito. Por campo pode entender-se «um espaço de posições e relações minimamente institucionalizadas ou então em processo

5 E temos, assim, um jornalismo semanal, quinzenal, mensal ou trimestral e, no outro extremo, encontramos jornais - televisivos, radiofónicos, telemáticos - que sāo editados e difundidos várias vezes por dia. Veja-se, sobre a questão da 'periodicidade', Ángel Benito (1995), especialmente pp. 125-135. 
de institucionalização», cuja autonomia se define «por relação à autonomia de todos os outros [campos] pertinentes, num modelo de co-determinação, segundo hierarquias complexas, variáveis e cruzadas, entre campos» 6. Além desta institucionalização e deste modelo de co-determinação, revelase pertinente a sugestão de Bourdieu de que o campo é um espaço social em que se jogam e conflituam relaçōes de forças de natureza económica, mas também simbólica ${ }^{7}$.

Tem-se associado a génese dos campos sociais à modernidade, num processo que, a partir dos séc. XV-XVI, se caracteriza, na proposta de Adriano Duarte Rodrigues, pela "ruptura» progressiva, mas evidente, relativamente à «ordem totalizante do religioso» que fora, até então, o elemento de aglutinação das diferentes dimensões ou esferas do social. O campo social constitui, ainda segundo aquele autor, "um sujeito de enunciação» que detém a «capacidade de impor com legitimidade indiscutível algo ao conjunto do tecido social» 8 .

O campo jornalístico constitui uma esfera com um relativo grau de especificidade e de autonomia no campo mediático 9, competindo-lhe, além do papel de mediação entre os diferentes campos sociais, o da enunciação-construção da informação de actualidade. Bourdieu entende-o como «lugar de uma oposição entre duas lógicas e dois princípios de legitimação": uma baseada em critérios internos e outra em critérios externos. Por um lado, o reconhecimento inter pares, que advém do grau de consonância com um conjunto de valores e de princípios socialmente construídos da profissão, bem como da adesão ou ruptura, implicação ou distanciamento face a eles; por outro o reconhecimento do público (número de espectadores, de leitores, reconhecimento e prestígio, veredicto do mercado) 10.

O quadro generalizado e omnipresente da lógica de mercado terá levado, na óptica de Bourdieu, à contaminação crescente do próprio campo jornalístico. Tal ocorreu especialmente com o impacte da lógica espectacularizante da televisão e porque, embora a produção jornalística se efectue

6 Recorro aqui ao traballho do sociólogo Augusto Santos Silva (1994) Tempos Cruzados: um Estudo Interpretativo da Cultura Popular. Porto: Afrontamento, p. 67.

7 Cf. Pierre Bourdieu (1994) Sur la Television, Suivi de l'Emprise du Journalisme. Paris: Liber, p. 46

8 Cf. Adriano Duarte Rodrigues (1990) Estratégias da Comunicação, Lisboa: Presença, p. 142 e 144.

9 Num texto de 1996, intitulado 'Journalisme et Éthique', Bourdieu precisa que a autonomia relativa do campo jornalístico é uma «faible autonomie», na medida em que se encontra «fortemente submetida a constrangimentos externos, como é o caso dos que são exercidos, directa ou indirectamente, pelos anunciantes, pelas fontes e também pela polítican.

10 Cf. Pierre Bourdieu (1994), op. cit., p. 83. 
necessariamente através de pessoas singulares, "os mecanismos de que o campo jornalístico é palco e os efeitos que estes exercem sobre os outros campos são determinados na sua intensidade e na sua orientação pela estrutura que o caracteriza» 11 . Ora, na mesma linha, a lógica específica do campo pauta-se sobretudo pela disputa de audiências - e logo pela 'cacha', pela primazia, pela velocidade, pela atenção-esquecimento, por um complexo jogo ora de mimetismo ora de distinção face à concorrência.

Bourdieu faz notar que a importância do campo jornalístico no sistema social advém do «monopólio de facto sobre os instrumentos de produção e de difusão de informação em larga escala», o qual the permite definir o acesso ao espaço público e à existência e notoriedade públicas, e sobretudo, «impor ao conjunto da sociedade os seus princípios de visão do mundo, a sua problemática, o seu ponto de vista». Para aquele sociólogo, este campo noticiabilidade - e os profissionais do jornalismo em particular - ao tomar em consideração apenas determinados aspectos da realidade que se articulam com as suas categorias de observação e os seus critérios de noticiabilidade exercem sobre o conjunto da sociedade, sem porventura disso se darem conta, uma "formidável censura» que tem a sua origem no «conjunto de pressupostos e de crenças» partilhadas no seu interior 12 .

Resta saber se esta 'lógica do sistema' e esta 'ideologia profissional' são de tal modo monolíticas e constrangedoras que impeçam a emergência e manifestação de lógicas contraditórias e de visões e procedimentos diferenciados. Este ponto merece ser considerado, para esclarecer em que medida nos movemos num quadro teoricamente determinista de relações entre campos ou, antes, num quadro em que os vários campos se co-determinam, de acordo com «hierarquias complexas, variáveis e cruzadas», como notávamos atrás. Sobre isto, é necessário considerar não apenas as dinâmicas conflituais e mesmo as lutas internas à por vezes assim chamada «classe jornalística» e ao campo jornalístico no seu conjunto, mas também a diversidade de trocas e de influências recíprocas do campo jornalístico com os restantes campos sociais.

Quanto ao primeiro destes pontos (a dinâmica interna do campo jornalístico), um aspecto que tem merecido atenção diz respeito ao modo como se conjuga a cultura profissional dos jornalistas com as lógicas e orientações editoriais e empresariais dos meios informativos. Ora, conforme faz notar Solowski (1993), além da especificação dos padrões e norrmas de comportamento pelas quais os jornalistas se devem pautar, o "profissionalismo jornalístico» envolve ainda outros mecanismos que funcionam simultaneamente como processo de controlo e como processo de diferenciação,

11 Cf. Pierre Bourdieu, op. cit., p. 87, itálico no original.

12 Idem, pp. 52-54. 
gerador de potenciais contradições. Um deles é a definição de políticas e de projectos editoriais ao nível de cada organização mediática, não necessariamente contraditórios com os valores e normas da profissão, mas que "localizam» e concretizam tais normas e valores com enfoques e ênfases distintos, tendo por base uma visão do papel da organização no espaço social mais amplo. O outro é o "sistema de recompensa profissional», concretizável quer pela via da ascensão hierárquica (diferenciação de 'status'), quer pela via do regime contratual e remuneratório individual (diferenciação económica), quer ainda pelas duas vias conjuntamente. Ou seja, a par de uma tendência igualizadora e homogeneizadora da «cultura profissional» incentivada pelas organizações profissionais (e eventualmente pelos quadros normativo-legais), verificam-se paralelamente mecanismos que introduzem no campo uma diferenciação ao nível do 'status' económico e simbólico dos actores e modos diferenciados de interpretar / concretizar organizacionalmente os valores e normas da profissão 13 .

O outro aspecto - a vasta gama de trocas políticas, económicas e simbólico-ideológicas, com outros campos sociais - não parece menos relevante, na linha de reflexão que temos vindo a equacionar. De facto, seja pela sua natureza de campo autónomo do espaço social, seja pela sua especificidade de instância mediadora dos restantes campos, o campo jornalístico distingue-se, justamente, por um lado, pela visibilidade social, que o torna objecto de uma constante apreciação, para não dizer escrutínio e vigilância públicos, porquanto expõe em permanência o produto do seu trabalho; por outro lado, porque representa, enuncia e interpreta aspectos e realidades de todos os outros campos, o que faz dele terreno de constantes disputas acerca da sua legitimidade social e simbólica para fazer o que é suposto que faça.

É certo que a referida mediação não se circunscreve nem é essencialmente - como se dá por vezes a entender - mero veículo ou amplificação dos eventos, acontecimentos e problemas, mas sim instância de definição e palco de representação da vida social. Isto ocorre ao lado - e em interaç̧ão-com outras instâncias e outros palcos, com os quais disputa (e face aos quais permanentemente define e redefine) a sua legitimidade de campo autónomo. Porém, uma coisa é analisar os eventuais desvios e distorções que o afectam - como pode estar a ocorrer, nas últimas décadas, com as incidências da comercialização e da espectacularização

13 Uma mesma lei de imprensa, um mesmo estatuto do jornalista (quando eles existem), um mesmo código deontológico podem servir de referência a jornalistas de órgãos ditos 'de referência' e a tabloides, a um órgão de serviço público e a um órgão comercial, ao meio de informação pertencente a um grande grupo transnacional e a um humilde jornal local. 
da informação - e outra bem diferente é o reconhecimento da lógica e papel específico do campo jornalístico no quadro dos demais campos sociais e enquanto instância simultaneamente por eles instituída e deles instituinte.

Assim, e em resumo, considero útil e operativo o recurso ao conceito de campo para tentar equacionar e compreender o lugar e papel do Jornalismo na sociedade. $\mathrm{O}$ campo estrutura-se em torno de valores, normas e procedimentos que se definem e redefinem permanentemente na relação com as lógicas, valores e normas de outros campos e do sistema social mais vasto. Entendo essa relação como um compromisso histórica e socialmente construído, de equilíbrio instável. Pela sua natureza, ressente-se dos ventos dominantes que sopram em cada contexto histórico e constitui, porventura, em certas conjunturas, um factor potenciador ou mesmo gerador desses mesmos ventos. Mas, em lugar de ser um bloco homogéneo e monolítico, é também ele trespassado pelas lutas, contradições e dinâmicas de mudança de qualquer outro campo social .

\section{Eixos e pressupostos para a formação em Jornalismo}

A relevância social do jornalismo não parece sofrer contestação. Nas sociedades modernas, os sistemas e as relações sociais distinguem-se certamente por uma crescente diferenciação e especialização funcional. Distinguem-se ainda por aquilo que Giddens (1992) designou como descontextualização, entendida como "separação das relaçōes sociais dos contextos locais de interacção e a sua reestruturação através de extensões indefinidas de espaço-tempo" (1992, p. 16). Através deste processo, inerente à construção da modernidade, opera-se um certo esvaziamento e estandardização do espaço e do tempo, deixando as actividades sociais de estar amarradas às relações de co-presença.

Os meios de comunicação e informação, quer enquanto dispositivos tecnológicos, quer considerados pelas mensagens que veiculam, em especial a informação de actualidade, permitem criar uma multidimensionalidade dos tempos e dos espaços, favorecendo novas recontextualizações das instituições e relações sociais.

Os mapas cognitivos e as representações que vamos construindo do mundo em que vivemos dependem em grande medida daquilo que o sistema mediático-jornalístico elege e faz aceder à visibilidade social. E este processo adquiriu contornos tais, que se pode dizer que o critério de notabilidade deixou, em boa medida, de constituir uma característica pertencente ou inerente em primeiro grau à substância dos eventos e ocorrências, para passar a depender da atenção e incidência sobre eles projectada pela notificação mediática. Os campos político, económico, cultural e despor- 
tivo, nomeadamente, vivem de tal modo um jogo de dependências e cumplicidades com o campo jornalístico, que quase se tornam incompreensíveis fora da área de visibilidade que dessa forma recebem.

Por outro lado, a informação converteu-se num dos mais florescentes sectores da actividade económica, nomeadamente com o desenvolvimento e a convergência das chamadas novas tecnologias da informação e comunicação e com a expansão das redes electrónicas de comunicação e das respectivas formas de acesso.

Um aspecto relevante, neste contexto, é certamente o do leque de desafios colocados pela 'explosão da informação', sob o ponto de vista da quantidade, da diversidade e da velocidade, e pelos impactes decorrentes das inovações constantes, ao nível das formas do seu armazenamento, utilização e distribuição. Esta proliferação, que alguns autores entendem constituir um risco e mesmo uma ameaça ${ }^{14}$, suscita problemas que constituem, em nosso entender, dificuldades indesmentíveis, mas também justificação acrescida do papel do jornalismo.

Ao alargar-se exponencialmente a informação disponível, crescem na mesma medida os problemas da sua validade e fiabilidade (Agostini, 1997), com a particularidade de qualquer pessoa ou instituição poder virtualmente passar a ser fonte difusora de informação. A estes riscos será de acrescentar ainda a carga simbólica e eufórica inerente à imagem das novas tecnologias, que leva ou pode levar a tomar por menos carente de confirmação ou apreciação crítica um dado ou informação delas proveniente 15 .

Aqui se vê, de modo eloquente, que as normas e convenções que caracterizam a 'profissionalidade' do Jornalismo - a localização de um facto no espaço e no tempo, a identificação dos protagonistas dos eventos, a citação das fontes, o recurso a critérios de valorização dos acontecimentos, para já não falar da obediência a um código deontológico a que os profissionais reconhecidos como tal estão obrigados - constituem um fundamental contrato (implícito) com o público, que lhe assegura, pelo menos, pontos de referência que concorrem para a qualidade da informação.

E precisamente neste quadro que importa caracterizar e analisar criticamente as representações comuns acerca do papel do Jornalismo e da

14 Neil Postman, por exemplo, vai ao ponto de considerar a proliferaçāo de dados e de informaçōes proporcionados pelas novas redes de comunicação como potenciadora de uma espécie de sida cultural, dado encontrar, nas sociedades em que se propaga, sistemas imunitários completamente destroçados (1990).

15 Referindo-se à sua experiência de cinco anos a observar comportamentos e atitudes numa escola dos EUA, uma bibliotecária observou que «os estudantes - e mesmo alguns professores - acreditam que algo a que tenham acesso através do computador é melhor do que se estiver contido num livron (http://inst.augie.edu/-asmith). Como é lógico, a questão coloca-se nāo apenas para o público em geral, mas também para os próprios jornalistas. 
actividade jornalística. Aparentemente, continua a ser válido o retrato que fez, em tempos, Umberto Eco, relativamente à ideologia reinante no meio profissional, designadamente no contexto italiano: «existe uma fonte da notícia, que é um dado da realidade independente; depois, a informação, que se encontra ao serviço da realidade objectiva, transforma os factos, a que teve acesso através da fonte, em mensagens, distribuindo-as aos destinatários»16.

Se os factos falassem por si, a tarefa dos jornalistas talvez fosse mais fácil de levar a cabo, mas também seria por certo mais técnica e burocratizada. Mas os factos - que já exprimem e encerram modalidades de percepção daquilo que ocorre à nossa volta - não são por si informação e não podem ser colocados ao dispor dos interessados se não for através da sua enunciação, isto é, através da linguagem, através de códigos e convenções sócio-culturais.

Os profissionais do jornalismo têm necessariamente de, em cada momento, mediante complicados processos de selecção e avaliação, construir relatos e interpretaçôes, a partir de dados e informações que procuram e recolhem de diferentes modos e em diversas fontes. $O$ processo produtivo ocorre frequentemente em condições de pressão - desde logo de espaço e de tempo - que exigem a definição de critérios de classificação e a implementação de rotinas de produção, para fazer face à imprevisibilidade e multiplicidade de áreas das ocorrências da vida social.

A avaliação do interesse e importância dos eventos e a capacidade de indagar o sentido e alcance dos acontecimentos e de sopesar a validade dos factos pressupõem uma formação humanística e sociocultural apurada e exigente.

De entre as qualidades ou virtudes que se torna imperioso cultivar, no exercício da profissão e no processo de formação dos jornalistas, a procura incessante da verdade constitui uma dimensão fundamental, tendo presente que, mais do que os resultados - afinal, estamos sempre diante de aproximações, percepções ou versōes da realidade-essa busca deve assentar nos processos ${ }^{17}$. Trata-se, evidentemente, de uma matéria que

16 Eco, Umberto (1979) 'Obbjetività dell'Informazione: il Dibattito Teorico e le Trasformazioni della Società Italiana', in VV. AA. Informazione: Consenso e Disenso. Milāo: Il Saggiatore. Cit. In Rodrigo Alsina, 1989, p.174.

17 Num ensaio recente, Bertrand Labasse (1997) defende a necessidade de encontrar modelos que possam ajudar a abordar a complexidade da vida social, o que poderia passar pela exploração de uma 'epistemologia aplicada à informação', que substituísse «esta absurda obrigação moral do resultado - dizer a verdade - [por] uma obrigaçāo moral dos processos". $\mathrm{O}$ autor explica, a este propósito, que, tal como ao médico não se exige que cure o doente, mas que o trate devidamente e que do cientista se nāo espera que nāo erre, mas que proceda correctamente nas suas démarches, assim também ao jornalista se deveria pedir que cuide 
dificilmente se ensina, mas que se pode promover, tomando nomeadamente os códigos deontológicos e as disposições jurídicas como referência, e que se torna sobretudo importante cultivar, desde logo ao nível das relaçōes sociais e dos processos que se instauram nas instituições (Alves, 1996). De resto, uma das formas de aprofundar esta busca permanente da verdade passa por alertar para a complexidade das situações com que o jornalista lida permanentemente. Mais do que indagações filosóficas sobre o que vem a ser a verdade, trata-se aqui de partir de casos e de problemas em que a verdade vai sendo procurada, construída, através de processos que envolvem com frequência o defrontar de estratégias e jogos mais ou menos sofisticados de dificultação, de ocultação e de engodo 18. A capacidade de indagação, de relacionamento de factos, de contextualização histórica e sócio-cultural e de interrogação são competências importantes a desenvolver, combinadas com uma boa dose de tenacidade e, certamente, de humildade.

Neste quadro, considero importante que a abordagem crítica ao fenómeno jornalístico tenha em conta e submeta a análise as categorias que predominam na captação da realidade social, ao nível da cultura profissional e das lógicas dominantes no sector. Parece-me de especial significado um aspecto enfatizado por diferentes autores, que consiste na hipervalorização do acontecimento, enquanto «medida» hegemónica de todas as escalas temporais ${ }^{19}$. Como observa Wolton e, na sua esteira, Mauro Wolf, esta preponderância do novo, do imediato e do visível, que caracterizam o incessante fluxo informativo que «inunda» o espaço público mediatizado opera ou favorece uma simplificação e uma fragmentação da vida social, as quais conflituam necessariamente com a reconhecida complexidade dos problemas de que a informação jornalística trata. Por definição, a complexidade não é facilmente compreensível; isto é, exige a aturada recolha de elementos, tempo para os relacionar e digerir. Deste ponto de vista, considera Wolf (1997), «estão a desenhar-se assincronias profundas entre o tempo da informação e o tempo do conhecimento, relativamente aos problemas sociais e suas possíveis soluçōes».

Esta parece ser uma orientaçăo coerente com uma outra dimensão que julgo ser de promover na formação dos estudantes de jornalismo: a actividade jornalística como serviço público. Isto não implica a defesa de posi-

mais dos processos e da respectiva explicitaçāo, desde que fique salvaguardada a sua liberdade de expressāo.

18 A título de exemplo: por altura dos Jogos Olímpicos de Atlanta, em Julho de 1996, a pessoa que deu conta da existência da bomba no Centenial Park passou, no espaço de poucos dias, de um simples desconhecido, a herói nacional, depois a psicopata e potencial assassino para ser, finalmente tido como inocente. 
cionamentos 'iluministas' sobre o papel do jornalismo ou atitudes que entendem o exercício dessa actividade como uma militância. Significa assumir que o jornalismo tem um papel social de grande importância, que proporciona (ou não) os elementos de que os cidadãos necessitam para tomar conhecimento dos assuntos de interesse comum e dos argumentos e modos de ver implicados nesses assuntos, para debater as possíveis soluções, para orientar as suas vidas, etc. Há, como notou Bourdieu (1996)., uma relação estreita entre este sentido de serviço público do jornalismo e as "condições de possibilidade de uma virtude civil, de que o jornalismo é um dos lugares de exercício privilegiado» 20.

Esta perspectiva coincide parcialmente com algumas preocupações e dimensões da corrente norte-americana do chamado jornalismo público, cívico ou comunitário ${ }^{21}$. Por outro lado, não parece conflituar nem com uma certa diversidade de projectos editoriais que podem existir em cada sociedade nem com a natureza pública ou privada dos meios de informação. De resto, o debate que tem existido no campo teórico e no campo político ${ }^{22}$, em torno de diferentes visões e análises do papel do jornalismo na sociedade tem tido o mérito, pelo menos, de trazer para a arena pública uma matéria de indesmentível relevância para o aprofundamento da democracia e o de chamar a atenção para os riscos de uma subordinação do jornalismo à lógica do mercado. Nesta linha, mais do que defender esta ou aquela posição, parece-me mais adequado proporcionar aos estudantes candidatos a jornalistas termos de referência para a reflexão, não sem sublinhar o pouco sentido e até ineficácia de discursos generalizadores e extremados que ora tendem a aceitar, ou até enaltecer, a diluição do jornalismo

19 Dominique Wolton chama-lhe «a tirania do acontecimento» (1995, p. 169-170).

20 O exercício dessa 'virtude civil', a que alude Bourdieu, passa por encontrar, nos próprios meios jornalísticos, processos que permitam promover e reforçar práticas 'virtuosas' (definidas como tal pelo conjunto dos profissionais) e desincentivar ou mesmo penalizar práticas 'viciosas'. Essa seria, em seu entender, uma via para reforçar a própria autonomia do campo jornalístico. De entre esses processos, Bourdieu destaca: a) a criaçāo de instâncias reguladoras da entrada na profissão; b) a crítica interna recíproca (pratica habitual noutros campos de produção cultural); c) a crítica externa, e em particular a análise sociológica objectivante.

21 Uma visão avaliativa de conjunto pode ser consultada em Lambeth et al. (1998). Convém notar, porém, que também o 'jornalismo público' pode ser pervertido e transformado numa actividade em que 'o cliente é quem manda', representando, de facto, uma nova e mais requintada modalidade de 'subordinaçāo do jornalismo a uma logica de mercado' (Frank, 1999) ou uma nova forma de populismo (Nordenstreng, 1997).

22 No caso da França, isso tem sido notório, designadamente com a intervenção pública em que se lançaram cientistas sociais e jornalistas como Pierre Bourdieu, Patrick Champagne, Serge Halimi e outros. Mas tambem no Reino Unido ou nos EUA, com as sucessivas derrapagens do jornalismo naqueles países, nos últimos anos, o debate tem sido intenso. 
num hibridismo que mistura as notícias com a publicidade e o entretenimento ${ }^{23}$, ora tendem a difundir uma ideia dos jornalistas e do jornalismo como mera 'correia de transmissão' ou instância de reprodução e amplificação dos interesses e mundividências das elites no poder.

\section{Entre as teorias e as práticas}

Quando se lê ou escuta os relatos dos estagiários dos cursos de comunicação social / jornalismo acerca da sua entrada nas redacções, após mais de quatro anos de estudo e de aulas, surge-nos, por vezes, a imagem do pára-quedista diante da experiência do seu primeiro lançamento ou do automobilista na primeira viagem que faz por sua conta e risco. Alguns falam mesmo do contacto com "a realidade», como se a formação académica fosse como que uma espécie de ficção, de voo alto e planado por sobre os segredos, os escolhos e o pragmatismo da realidade «cá de baixo».

Enquanto crítica mais ou menos velada ao eventual (mas sempre repisado) teoricismo da formação académica, crítica que, independentemente da sua pertinência, diria ser inerente à condição estudantil, este sentimento é, a meu ver, inevitável, mesmo na hipótese de a componente mais orientada para o domínio das competências de execução ser mais desenvolvida. $E$ isso acontece porque o jornalismo não é um mero campo de estudo e análise, mas é também uma actividade profissional «de grande dificuldade e de grande complexidade», como observa justamente Nelson Traquina (1993, p.12). Os futuros profissionais devem, sem dúvida, ser preparados para essa complexidade, estar armados de uma competência multifacetada para compreender e interpretar o mundo em que vivem e analisar eficientemente a multiplicidade de códigos e de linguagens através dos quais a cultura e a vida social se enunciam. Mas não podem deixar, também, de estar familiarizados com as dimensões técnico-profissionais, éticas e estéticas da actividade e dos contextos do exercício da actividade. Como defendeu, em tempos, Adriano Rodrigues, "mais do que memorizar e treinar regras fixas de escrita jornalística, a formação tem cada vez mais como objectivo criar condiçōes de disponibilidade, ensinar a aprender, a reconhecer os sinais premonitores das mudanças significativas no tecido social por entre a fluidez das manifestações sociais, políticas, económicas, culturais que emergem por todo o lado» (1985). Partilho esta orientação que, no entanto, não pode ser contraposta à também necessária familiarização progressiva com a produção e redacção jornalísticas. Pelo contrário, quer a análise do trabalho dos profissionais no activo, quer os ensaios de produção própria podem ser - e de facto, pela experiência que possuo, têm sido - um caminho adequado e complementar de apreender o carácter complexo da actividade de jornalista. De resto, e como observamos com 
frequência, se há críticos implacáveis dos jornalistas e do jornalismo, os candidatos a jornalistas contam-se entre eles. Ora, o adentrar-se no lado mais prático da actividade não pode ser um mero desenvolvimento ou ilustração das perspectivas teóricas ou uma mera estratégia de natureza metodológica, mas antes, e também, uma via de desconstrução de visões mitificadas e idealizadas da profissão.

Julgo, por outro lado, vantajoso que a formação decorra de modo a que estes profissionais se possam familiarizar com uma compreensão crítica do vasto campo comunicacional. Isto significa que não me parece vantajosa a implementação de um percurso académico que encerre excessivamente a formação num determinado saber-fazer profissional. Ao mesmo tempo, torna-se necessária alguma prudência face às orientações e mesmo pressões, oriundas do mercado de trabalho, no sentido de se reduzir a ênfase na formação para determinados perfis profissionais específicos - jornalismo, publicidade, relações públicas, comunicação institucional, produção e realização audiovisual ou outros - em benefício de um perfil de 'comunicador' generalista, um polivalente 'topa-a-tudo', capaz de se adaptar futuramente a todo o tipo de oportunidades com que lhe venha a deparar. Tal formação omnibus pode ser funcional face a um contexto económico e cultural em que a informação é reduzida à comunicação ou, pelo menos, submetida à lógica de sedução e de encenação que frequentemente a caracteriza. Não parece, no entanto, ser essa uma via que sirva um jornalismo entendido como serviço à consciência e participação cívicas e ao enriquecimento da vida democrática. Uma coisa é os estudantes, ao longo do seu itinerário de formação, aprofundarem os seus conhecimentos acerca dos vários domínios da comunicação, até como forma de se situarem melhor - e, quem sabe, se redefinirem - face a opções já desenhadas; outra bem diferente reside na definição de um itinerário preferencial específico, que estruture o caminho a seguir e em função do qual se estabeleçam as prioridades e as precedências, numa lógica formativa caracterizada pela sequencialidade, a coerência e a aproximação progressiva - a culminar no estágio - ao mundo profissional.

\section{A formação de jornalistas e a Universidade portuguesa}

O ensino do jornalismo no seio da instituição universitária teve de defrontar-se com resistências várias, umas situadas no campo profissional e empresarial, outras provenientes do interior da própria Universidade. No primeiro caso, precisou de esbater as reticências e suspeições decorrentes de uma visão instrumental e tecnicista da formação de jornalistas que tende a sublinhar o carácter «excessivamente teórico» do ensino desta 
matéria nas instituições universitárias 24; no segundo caso teve de conquistar o seu próprio espaço, demarcando-se das concepções que, nas palavras de Adriano Duarte Rodrigues (1985), «entendem confinar a Universidade nos campos consagrados das disciplinas constituídas, olhando com desprezo para domínios marginais a esses campos disciplinares» 25.

Está por fazer a história do jornalismo português e, por extensão, a história do ensino do jornalismo. Dos dados disponíveis ${ }^{26}$ pode dizer-se que Portugal está presente logo nos primeiros momentos em que se debateu, na Europa, em finais do século XIX, a pertinência de formar jornalistas e a melhor via para o fazer ${ }^{27}$. Significativamente, as três vias que

23 Manuel C. Chaparro analisou esse fenómeno num texto publicado no site do Instituto Gutemberg e intitulado "O jornalismo não será reduzido a produto» (www.igutenberg.com.br/ chapa21.htm).

24 Veja-se, por exemplo, a sintese das II Jornadas sobre o Acesso à Profissão, publicada no boletim Jornalismo, de Janeiro de 1993, p.4, editado pelo Sindicato dos Jornalistas. Aí se critica com vigor nāo apenas o imputado teoricismo, mas igualmente o alheamento face às exigências da profissão e do mercado de trabalho. Por outro lado, não deixa de ser significativo que, na introdução geral a Jornalismo: Questões, Teorias e 'Estorias', Nelson Traquina tenha sentido necessidade de advertir que «a postura crítica do estudo e da investigação académica (...) nāo pretende denegrir os jornalistas mas, sim, compreender a actividade jornalística e o produto resultante dessa actividade - as notícias" (p.12).

25 Rodrigues, Adriano D. (1985) Princípios para um Projecto de Formação de Jornalistas em Portugal. Intervençāo no seminário "Jornalismo no ano 2000", realizado no Fórum Picoas, Lisboa (policopiado).

26 Foi-nos de utilidade, neste ponto, a consulta de alguma documentaçāo disponível, já por nós utilizada em trabalho anterior (cf. Pinto, M.; Sousa, H. 1999) e nomeadamente da seguinte bibliografia:

Correia, F. (1995). Contributo para o Estudo do Ensino do Jornalismo em Portugal. Lisboa (trabalho académico, fotoc.). Este texto viria a ser publicado com o mesmo título in $O$ Professor, n. ${ }^{\circ} 44$, III Série, Maio-Junho de 1995, pp. 53-61.

França, E.; Marques, G. B. (1982). 'O Acesso à Profissão de Jornalista'. In Liberdade de Expressão, Expressão da Liberdade: Conclusões, Teses, Documentos do $1 .^{\circ}$ Congresso dos Jomalistas Portugueses. Lisboa: Secretariado da Comissāo Executiva.

Marcos, L. H. (1986) 'Formação Profissional: Começo e Futuro', in Conclusões, Teses e Documentos do $2 .^{\circ}$ Congresso dos Jornalistas Portugueses. Lisboa: Secretariado da Comissāo Executiva

Rodrigues, J. C. (1986). O acesso à profissão de jornalista. In Conclusões, teses $e$ documentos do $2 .^{\circ}$ Congresso dos Jornalistas portugueses. Lisboa: Secretariado da Comissão Executiva

Mesquita, Mário; Ponte, Cristina (1996/97) Situação do Ensino e da Formação Profissional na Área do Jomalismo. Estudo elaborado para a Representaçāo da Comissāo Europeia em Portugal.

Tengarrinha, J. (1989). História da Imprensa Periódica Portuguesa (2. ${ }^{\mathrm{a}}$ ed.). Lisboa: Editorial Caminho.

${ }^{27}$ Quando a imprensa se tornara já um fenómeno de massas, pelo menos nos países mais avançados da Europa e da América do Norte, com consequências evidentes nos campos económico e profissional, o Congresso Internacional de Imprensa, que começou por se reunir 
então se defrontavam - a formação pela experiência (na 'tarimba', como também se diz), a formação técnica e a formação cultural e humanística de nível superior - continuam a figurar nos debates de hoje, se bem que a primeira modalidade tenha vindo a perder claramente terreno.

Sendo, porém, o jornalismo um dos esteios do espaço público, não será de todo surpreendente que as condições do seu exercício e os modos de o encarar e assumir no quadro académico dependa das características que, num determinado sistema social, reveste esse mesmo espaço público.

Poder-se-ia supor que, num regime autoritário e censório, como foi o do chamado Estado Novo, o Governo tivesse procurado criar e controlar a formação dos jornalistas, enquanto forma e instância acrescidas de controlo ideológico. Sabemos que não foi essa a orientação seguida, o que, em certa medida, e conhecendo o controlo férreo exercido sobre os órgãos de informação e sobre os respectivos profissionais, diz bastante da concepção e atitude do salazarismo relativamente aos jornalistas. Sintomaticamente, até Abril de 1974, a iniciativa na matéria coube, de uma forma mais saliente, ao Sindicato da classe 28 e, já na era marcelista, a um grupo financeiro com interesses em várias publicações. Tudo (ou quase tudo) iniciativas sem sequência ou, como no último caso, sem reconhecimento oficial.

A posição do regime derrubado em 25 de Abril relativamente às ciências da comunicação e ao jornalismo deve ser entendida num quadro mais

pela primeira vez na Bélgica em 1894, viria a reunir-se, na sua quinta edição precisamente em Lisboa, em 1898, para aprovar uma moção em que se defendia a necessidade da formação dos jornalistas, não tanto em matérias teóricas, mas em questōes práticas como o uso da máquina de escrever, do telefone e do telégrafo, rotinas redactoriais, gestão e contabilidade, impressāo e distribuição, além de noçōes de reportagem em tribunais e parlamentos. A ideia geral era a de que este tipo de formação deveria ser promovida e organizada pelas organizaçōes profissionais e não pelo Estado. Cf. Bjork, U. J. (1996) "The European Debate in 1984 on Journalism Education', in Journalism \& Mass Communication Educator, vol. 51 (1), pp. 68 e ss.

28 O Sindicato, através do seu presidente, Luís Teixeira, apresentou ao Governo, a 8 de Fevereiro de 1940, o projecto detalhado de um Curso de Formaçāo de Jornalistas, com o respectivo elenco e programa de cadeiras, bem como o nome dos responsáveis por cada uma delas. A iniciativa, no entanto, nāo encontrou acolhimento favorável junto do Governo. Em 1970, sob a direcçāo do jornalista Silva Costa, a Assembleia Geral do Sindicato aprovava um ambicioso 'Projecto de Ensino de Jornalismo em Portugal», que havia sido elaborado por uma comissão constituída pelos jornalistas Silva Costa, Jacinto Baptista, António dos Reis, João Gomes e Cáceres Monteiro, a que foram associados consultores técnicos recrutados entre portugueses diplomados em Jornalismo por escolas superiores de Espanha, França e Itália (cf. Correia, op. cit.). O projecto propunha um curso de licenciatura em cinco anos com um peso maioritário ( 60 a 70 por cento) de disciplinas de ciências sociais e humanas. Citando uma recomendação da UNESCO, Silva Costa sublinhava então que «o jornalista no mundo moderno, necessita de ampla base cultural e da maturidade própria de um diplomado pela Universidade" (cit. in Agee, W.K.; Traquina, N. (198?) O Quarto Poder Frustrado - Os Meios de Comunicação Social no Portugal Pós-Revolucionário. Lisboa: Ed. Vega, p.124. 
geral de desinteresse, menosprezo ou mesmo de suspeita perante as ciências sociais em geral e de um controlo centralista das instituições de onde poderia porventura emergir a proposta de iniciativas 29 .

No pós-25 de Abril, passada que foi a agitação e criatividade do período revolucionário, vão desenvolver-se três linhas de acção, correspondentes a outras tantas concepções e orientações quanto à formação de jornalistas: a profissional (promovida ou co-participada por organizações profissionais e marcada por uma concepção da formação como reciclagem e actualização); a politécnica (afirmando a relevância de uma legitimação e certificação de nível superior, mas voltada para as exigências do mercado de trabalho); e a universitária (valorizadora de uma sólida formação cultural e humanística e com um grau diferencial de aproximação à prática profissional) ${ }^{30}$. Neste último caso, haveria que distinguir ainda, como fazem notar Agee e Traquina (s/d: p.124), a concepção que defende que o campo jornalístico deve ser objecto de abordagem em estreita interacção com os outros campos, no quadro mais vasto das ciências da comunicação, daqueloutra que preconiza a autonomização dos cursos de Jornalismo, como veio mais tarde a acontecer com o curso criado na Faculdade de Letras da Universidade de Coimbra.

$\mathrm{Na}$ leitura desta problemática feita por Mário Mesquita, as licenciaturas universitárias, quer as que se orientam por uma 'perspectiva comuni-

29 Quanto às universidades, importa sublinhar que, "de 1926 até à publicação da lei Veiga Simão [1973], durante quase meio século, o ensino superior não mereceu grande empenho do Estado Novo». Em 1960, por exemplo, era escassíssima (3.9\%) a população portuguesa da faixa 18-22 anos que frequentava o ensino superior; por alturas do 25 de Abril de 1974, apesar dos progressos entretanto registados, essa proporçāo nāo andava longe dos 10 por cento ${ }^{63}$. É interessante notar também que os estudantes que frequentavam em 1960 cursos superiores no âmbito das ciências sociais não iam além dos $6.4 \%$ do total de alunos. Em 1970, essa percentagem andava pelos 11\%, elevando-se, a partir de 1975, a valores próximos dos 20 por cento (cf. Carreira, H. Medina (1996) 'A Educaçāo', in Barreto, A. (org.). A Situação Social em Portugal, 1960-1995, Lisboa: Instituto de Ciências Sociais, p. 442).

30 O CFJ - Centro de Formação de Jornalistas (criado no Porto por um conjunto de jornalistas em 1983) bem como o CENJOR - Centro Protocolar de Formaçāo de Jornalistas (criado em 1986, em Lisboa, por iniciativa do Sindicato dos Jornalistas, Associações de Imprensa Diária e Não-Diária e Instituto de Emprego e Formaçāo Profissional) seriam exemplos da primeira orientação enunciada. Os cursos de jornalismo ou aparentados nascidos no quadro de desenvolvimento da rede do ensino superior politécnico seriam exemplificativas da segunda orientação. Finalmente os cursos de ciências da comunicação criados, primeiro, na Faculdade de Ciências Sociais e Humanas da Universidade Nova de Lisboa, e, depois, no Instituto Superior de Ciências Sociais e Políticas da Universidade Técnica de Lisboa, na Universidade Católica, na Universidade da Beira Interior e na Universidade do Minho, além de, mais recentemente, em várias universidades do sector privado, exemplificariam a terceira orientação. O primeiro curso de licenciatura em Jornalismo foi criado na Faculdade de Letras da Universidade de Coimbra em 1993. 
cacional' quer as que seguem uma 'formação humanista clássica' acompanhada de disciplinas mais especificamente relacionadas com a vida profissional, encaram a especialização em jornalismo numa perspectiva que «liga e associa a formação humanista à competência técnico-profis-sional» 31 . Um exemplo desta articulação pode ser encontrado precisamente na licenciatura em Comunicação Social da Universidade do Minho, que define como objectivos o desenvolvimento de uma tríplice competência do 'comunicador social' a formar:

«- competência intelectual, cultural e moral que lhe permita a compreensão e interpretação críticas da sociedade e mundo actuais;

«- competência específica no âmbito da comunicação humana, mediante o conhecimento aprofundado dos comportamentos comunicativos, seus aspectos psicológicos e sociais e processos semióticos e linguísticos, e também a capacidade de emitir e receber mensagens com elevado grau de eficiência;

"- competência técnico-profissional ao nível dos meios de comunicação e do exercício de funções de comunicação institucional em algum sector especializado» 32 .

Pode haver divergências quanto ao peso relativo que estes três eixosorientações deverão ter no currículo formativo ou quanto ao modo de os operacionalizar. Haverá, hoje, provavelmente um acentuado grau de concordância em que todos eles devem figurar. É certo que continua a registar-se uma corrente de opinião entre os jornalistas mais veteranos, segundo a qual a verdadeira formação é a da tarimba (sur le tas, diriam os franceses). E é preciso reconhecer que esta asserção possui alguma dose de verdade. Até porque cada 'tarimba' representa um contexto muito particular, com a sua história, as suas rotinas, a sua cultura organizacional, e seria impossível à formação académica contemplar toda essa diversidade. Mas também é necessário perguntar-se o que são hoje as redacções e se, quando se faz a apologia da tarimba, não se está a idealizar e mitificar uma realidade que se diversificou e se tornou até, em diversos casos, irreconhecível. Por outro lado, a complexidade crescente da vida social, a proliferação das fontes e das formas de informação, as transformações no plano sócio-económico e também no plano cultural e ético induzidas pelas inovações tecnológicas tornam cada vez mais pertinente a ideia de que a

31 Mesquita, M. (1995). L'Enseignement du Journalisme au Portugal: le Miracle de la Multiplication des Cours. Texto apresentado no Sigma/Communication Sciences Meeting em Sienna, Itália, 22-23 de Setembro (fotocopiado).

32 Preâmbulo da Resolução SU - 3/91 do Senado da Universidade do Minho, que instituiu o Curso de Comunicação Social. 
formação não se confunde com uma etapa que precede o exercíco de uma profissão ou de uma actividade social, antes deve ser, cada vez mais, "educação ao longo da vida» a qual, no dizer da UNESCO, constitui «uma das chaves de entrada no século XXI» 33. Eis um desafio não apenas para os jornalistas e suas organizações sócio-profissionais e para as empresas, mas também para as próprias instituiçōes de formação de nível superior.

33 Delors, Jacques (coord.) (1996) L'Éducation, un Trésor Est Caché Dedans. Rapport à l'UNESCO de la Commission Internationale sur l'Education pour le XXIème Siècle. Paris: Éditions Odile Jacob, p. 17 e 108-122. 


\section{REFERÊNCIAS BIBLIOGRÁFICAS}

Agee, W. K.; Traquina, N. (198?) O Quarto Poder Frustrado - Os Meios de Comunicação Social no Portugal Pós-Revolucionário. Lisboa: Ed. Vega, p.124.

Agostini, Angelo (1997) 'Les Nouveaux Réseaux de Communication, Atout ou Menace pour la Presse: le Journalisme au Defi d'Internet', in Le Monde Diplomatique, Outubro, pp. 26-27.

Alves, Aníbal (1996) A Etica, os Media e as Ciências Sociais na Perspectiva da Formação dos Mediadores/Jomalistas. Intervenção nas Confexências da Arrábida sobre «A Ética, a Credibilidade e o Mercado dos Media», em 23 de Julho (polic.).

BENrTo, Ángel (1995) La Invención de la Actualidad: Técnicas, Usos y Abusos de la Informacion. Cidade do México: Fondo de Cultura Económica.

BJORK, U. J. (1996) 'The European Debate in 1984 on Journalism Education', in Journalism \& Mass Communication Educator, vol. 51 (1).

Bourdieu, Pierre (1994) Sur la Télevision, Suivi de l'Emprise du Journalisme. Paris: Liber.

Bourdieu, Pierre (1996) 'Journalisme et Éthique', in Les Cahiers du Journalisme, n. ${ }^{\circ}$, Junho (também disponivel on-line in: www.homme-moderne.org/societe/socio/bourdieu/ Bjournal.html).

CARreira, H. Medina (1996) 'A Educaçāo', in Barreto, A. (org.). A Situação Social em Portugal, 1960-1995, Lisboa: Instituto de Ciências Sociais, p. 442).

ChaparRo, "O Jornalismo Não Será Reduzido a Produto», texto consultado in: www.igutenberg.com.br/chapa21.htm, site do Instituto Gutemberg (Brasil).

Chaparro, Carlos (1999) 'Deixamos de Ser Protagonistas. Ainda Bem', in O Ribatejo, 22 de Julho.

Correia, F. (1995). Contributo para o Estudo do Ensino do Jomalismo em Portugal. in O Professor, n. ${ }^{\circ} 44$, II Série, Maio-Junho de 1995, pp. 53-61.

DELoRs, Jacques (coord.) (1996) L' Éducation, un Trésor Est Caché Dedans. Rapport à l'UNESCO de la Commission Internationale sur l'Éducation pour le XXI.ème Siècle. Paris: Editions Odile Jacob.

Eco, Umberto (1979) 'Obbjetività dell'Informazione: il Dibattito Teorico e le Trasformazioni della Società Italiana', in VV. AA. Informazione: Consenso e Disenso. Milāo: Il Saggiatore. Cit. In Rodrigo Alsina (1989) La Construcción de la Noticia, Barcelona: Paidós.

FrançA, E.; Marques, G.B. (1982). 'O Acesso à Profissão de Jornalista'. In Liberdade de Expressāo, Expressão da Liberdade: Conclusōes, Teses, Documentos do $1 .^{\circ}$ Congresso dos Jornalistas Portugueses. Lisboa: Secretariado da Comissão Executiva.

Frank, Thomas C. (1999) 'Newseum, le Musée qui Enterre le Journalisme', in Le Monde Diplomatique, Agosto, p. 10.

García Marquez, Gabriel (1996) 'El Mejor Ofício del Mundo', in El País , 20 de Junho.

Gomis, Lorenzo (1991) Teoría del Periodismo. Barcelona: Paidos.

LABASSE, Bertrand (1997) 'Repenser l'Information? Vieux Schémas et Nouveaux Enjeux', in Les Cahiers du Journalisme, n. 3 , pp. 26-35, Junho (URL: www.univ-lyon 1.fr/spr/GEV).

LAMBETH, Edmund; Ph. Meyer; E. Thorson (eds.) (1998) Assessing Public Journalism. Columbia, Mi.: University of Missouri Press. 
Marcos, L. H. (1986) 'Formação Profissional: Começo e Futuro', in Conclusôes, Teses e Documentos do $2 .^{\circ}$ Congresso dos Jornalistas Portugueses. Lisboa: Secretariado da Comissāo Executiva.

Martínez-Albertos (1997) El Ocaso del Periodismo. Barcelona: Editorial CIMS.

MesquitA, M. (1995) L'Enseignement du Journalisme au Portugal: le Miracle de la Multiplication des Cours. Texto apresentado no Sigma/Communication Sciences Meeting em Sienna Itália, 22-23 de Setembro (fotocopiado).

Mesquita, Mário; Ponte, Cristina (1996/97) Situação do Ensino e da Formaçāo Profissional na Área do Jornalismo. Estudo elaborado para a Representação da Comissão Europeia em Portugal.

Nordenstreng, Kaarle (1997) 'The Citizen Moves from Audience to Arena', in Nordicom Review, n. 2.

PinTo, Manuel; Sousa, Helena (1999) 'Journalism Education at Universities and Journalism Schools in Portugal', in Fröhlich, Romy \& Christina Holz-Bacha (eds) Journalism Education in Europe and North America: an International Comparison. Hampton Press (no prelo).

PostMan, Neil (1990) Informing Ourselves to Death. URL: http://cec.wustl.edu/ cs142/articles/MISC/informing_ourselves_to_death-postman.

RAMONET, Ignacio (1999) 'La Fin du Journalisme - Debat avec Ignacio Ramonet'. Entrevista dada a ACRIMED - Action Critique Médias (www.samizdat.net/acrimed/bulletin/ Ramonet.html).

Rodrigues, Adriano D. (1985) Principios para um Projecto de Formação de Jornalistas em Portugal. Intervenção no seminário «Jornalismo no Ano 2000 », realizado no Fórum Picoas, Lisboa (policopiado).

Rodrigues, Adriano Duarte (1990) Estratégias da Comunicação, Lisboa: Presença

RoDrigues, J. C. (1986) 'O Acesso à Profissāo de Jornalista', in Conclusões, Teses e Documentos do 2. ${ }^{\circ}$ Congresso dos Jomalistas Portugueses. Lisboa: Secretariado da Comissāo Executiva

SolowsKI, John (1993) 'O Jornalismo e o Profissionalismo: Alguns Constrangimentos ao Trabalho Jornalístico', in Nelson Traquina (org.) Jormalismo: Questōes, Teorias e 'Estórias'. Lisboa: Vega (texto originalmente publicado em 1989).

Tengarrinha, J. (1989) Historia da Imprensa Periodica Portuguesa (2." ed.). Lisboa: Editorial Caminho.

TRAQUINA, Nelson (1993) Jornalismo: Questöes, Teorias e 'Estórias', Lisboa: Vega.

Wotron, Dominique (1995) 'O Espaço Público Mediatizado', in Revista de Comunicação e Linguagem, 21-22. 